\title{
The Problem of Developing Schoolchildren's Cognitive Activities in the Educational Process
}

\section{El problema de desarrollar las actividades cognitivas de los escolares en el proceso educativo}

\author{
Vera Benediktovna Tsarkova* \\ Lipetsk State Pedagogical P. Semenov-Tyan-Shansky University, Lipetsk, Russia \\ ORCID: https://orcid.org/0000-0002-1921-9382 \\ Lyudmila Nikolaevna Belenikina \\ Lipetsk State Pedagogical P. Semenov-Tyan-Shansky University, Lipetsk, Russia \\ ORCID: https://orcid.org/0000-0001-8572-3408 \\ Tatyana Yuryevna Vasilyeva \\ Lipetsk State Pedagogical P. Semenov-Tyan-Shansky University, Lipetsk, Russia \\ ORCID: https://orcid.org/0000-0003-4894-9816
}

Received 02-12-20 Revised 01-23-20 Accepted 05-13-20 On line 07-29-20

*Correspondence

Email: vera.b.tsarkova@yandex.ru
Cite as:

Tsarkova, V.B., Nikolaevna Belenikina, L., \& Yuryevna Vasilyeva, T. (2020). The Problem of Developing Schoolchildren's Cognitive Activities in the Educational Process. Propósitos y Representaciones, 8 (SPE2), e639. Doi: http://dx.doi.org/10.20511/pyr2020.v8nSPE2.639 


\section{Summary}

This article aims to a research problem that emphasizes the necessity to guide and organize schoolchildren's cognitive activities. In a situation when cognition becomes the leading activity, new opportunities are opened up for the organization of the whole educational process, including its other aspects such as - development, and learning. The experiment conducted revealed problem points of organizing the process of cognition as well as the necessity for collecting additional data for a future experiment. The paper also puts forward the idea of a correlation between the hierarchical system of principles of education and types of adequacy.

Keywords: Human Activity; Cognitive Activity; Cognitive Mechanisms; Schoolchildren's Cognitive Resources.

\section{Resumen}

Este artículo apunta a un problema de investigación que enfatiza la necesidad de guiar y organizar las actividades cognitivas de los escolares. En una situación en la que la cognición se convierte en la actividad principal, se abren nuevas oportunidades para la organización de todo el proceso educativo, incluidos sus otros aspectos, como el desarrollo y el aprendizaje. El experimento realizado reveló puntos problemáticos de organizar el proceso de cognición, así como la necesidad de recopilar datos adicionales para un experimento futuro. El documento también plantea la idea de una correlación entre el sistema jerárquico de principios de educación y los tipos de adecuación.

Palabras clave: Actividad humana; Actividad cognitiva; Mecanismos cognitivos; Recursos cognitivos de los escolares.

\section{Introduction}

Life places a lot of demands on modern man. In order to meet these demands, modern man has to be not only ethical and spiritually and physically strong, but also efficient with a creative and action-oriented personality.

The driving force defining a person's development "lies in the person's activity as a flexible system of different types and forms" (Kagan 1974, p.269). The notion of "the leading activity" introduced by Vygotsky (1982) allows to determine the dominant activity around which all the other types (communication, value-orientation artistic labor activity, cognition, play) can be grouped.

Here it is necessary to mention Bruner's book “Beyond the Information Given: Studies in the Psychology of Knowing" (1977), in which the scholar analyzes perception processes, problems of the psychology of thinking, as well as problems of the psychological development of a child. Bruner considers concept formation and categorization as the major forms of cognitive activity. Brushlinsky's work (1990), which stresses the interaction of someone cognizing the world and the world per se, may also be regarded as a step toward solving the problem of cognitive activity.

The research presented in the paper is focused on cognitive activity since cognition becomes the leading activity of someone who starts school. The development of his or her intellect is affected by the assimilation of cognitive information based on the work of the cognitive mechanisms of the psyche, creating the necessary prerequisites for the formation of all personality traits.

Schoolchildren's cognition is only possible within the framework managed by the school in order to help them master the existing system of knowledge. This system was developed by representatives of previous generations and is constantly enriched by the achievements of their successors. Here cognition manifests itself in its three types - mundane, artistic, and scientific, 
which are responsible for the result of the cognitive activity in the corresponding spheres and which are correlated with three subsystems of the general system of knowledge.

In the framework of the aforementioned parameters and school curricula, each pupil acquires his or her own experience in cognitive activity. He or she has to understand the specific nature of modern cognition and its problems as well as attempt to explore the correlation between knowledge and reality.

A prerequisite for a successful solution of these tasks is the creation of such educational conditions in which schoolchildren's sense experience is combined with thinking (in our case with speech thinking), when studying various texts (in the most general, semiotic sense of the word) have a deep socio-cultural meaning for them. A whole set of pertinent questions arise:

- How successful is this process at school?

- Does school ensure the development of cognition as a type of activity?

- Does school allow its pupils to go beyond the information given?

- Does cognition entail other types of activity, and how explicit (tangible) are they?

All cognitive learning activities are geared towards pushing students to work through different problems and stimuli. The goal is to get them thinking and applying problem-solving strategies without the use of preparation or steps that lead to an answer. You want to craft activities that will make your student apply logic, creativity, and close examination on the spot to produce an answer. Cognitive learning essentially relies on five principles: remembering, understanding, applying, evaluating, and creating. Below is a breakdown of each principle and some activities students can do that correspond to each.

\section{Remembering}

Activities that rely on remembering ask for the student to recall previously learned information to complete the task at hand. This might be a great review for the beginning of class to see if students are comprehending previous lessons. A couple of activities might be:

- Creating a timeline of important events from memory

- Make a game of reciting poetry or important writings

- Writing a paragraph or blurb detailing what they remember from last class

\section{Understanding}

Understanding activities directly engage students to see how they interpret information. This is a particularly broad category that draws on students being able to analyze information from different angles and to recognize, interpret, and classify it. Here are a few activity ideas:

- Defending a point of view, or debate

- Creating a list of examples

- Classifying types of processes or events

\section{Applying}

Part of problem-solving has to do with applying specific skills and knowledge to produce the proper result. Push your students to rely on what they've learned and figure out ways to succeed through fun activities: 
- Have the students create an effective learning game themselves

- Solve problems or answer questions listed on the board

- Have students demonstrate procedures in front of class

\section{Evaluating}

This principle focuses on analyzing information and making judgments based on it. Students will weigh information based on criteria previously learned. A few activities for your students can include:

- Constructing a graph to illustrate certain information

- Having students develop a questionnaire to group or gather information at hand

- Creating a pros and cons list

\section{Creating}

Cognitive learning is centered on adapting to new stimuli and constructing methods to solve problems or address needs. Creative activities rely on students to produce original ideas to address prompts, organize thoughts, and devise a means of their own invention that will help them answer problems. These are just a few creating activities:

- Write an original poem

- Perform or write a scenario demonstrating themes or illustrating specific ideas

- Write a manual or guidebook demonstrating important information

In the history and theory of pedagogy theory existed diverse selection of educational content. Theory of didactic materialism claimed that the main purpose of education is to transfer the student as much as possible the amount of knowledge from various fields of science. Theory of didactic utilitarianism claimed that the main criterion that should guide the definition of the content and learning, is the reconstruction of the social experience, a variety of practical exercises should play the role of factors, activating the thinking and activities of the students. For the methodology for determining the content of higher education, until recently, it was typical signs of the first theory. We put forward a variety of requirements for the content and organization of development of normative and methodical documentation of high school; in the formation of educational material implemented extensive approach, based on the increasing differentiation of disciplines and expand the scope of study program. Scientists didacticians higher school have all become increasingly turn to the theories of the content of general education, in particular, to the content of education theory, developed under the leadership of I.Ja. Lerner (1981) and M.N. Skatkin (1986), according to which the basis for justification of detention education should be the position of the unity of the substantial and remedial parties of training. According to this theory the basis of the content of education should be the position of the unity of the parties, and the content cannot be reduced only to the list of knowledge and skills on subjects should include the various elements of social experience. Having more and new theories. The theory of humanistic education - one of the leading theories of pedagogy US since the late 60-ies. The main objectives of this theory: $3 / 4$ education of a free individual, which has a solid self-control and capable of selfrealization; $3 / 4$ human education, which can love, to feel deeply, to create and to continue the process of self-education; $3 / 4$ creating the necessary conditions for the development of all the potentialities inherent in man - the desire for learning and self-development, inherent in any normal individual. Clearly, student engagement is a rich research area. Educators must continue to seek to understand and apply specific, well-considered, if not agreed upon, strategies that support student engagement in learning both in and beyond the classroom. The consequences of not engaging students in learning are reportedly dire (Prensky, 2001; Tapscott, 1998; Gilbert, 2007; Willms, 2003; Claxton, 2007; Zheltukhina et al., 2016; Chizh et al., 2016). "Some educationists consider engaging disengaged pupils to be one of the biggest challenges facing 
educators, as between 25\% (Willms, 2003) and over 66\% (Cothran \& Ennis, 2000) of students are considered to be disengaged" (as cited in Harris, 2008). It is obvious that students live in world that engages them differently than the world their parents experienced. That students respond to this world and have changed over the last twenty years in response to their engagement within a technology rich society and changes in upbringing almost goes without saying. How schools respond is key to student success. A great issue might be that students leave school incapable of or unprepared for a productive and healthy life in the "Knowledge Society" in which they will live and lead (Gilbert, 2007). If we fail to change our pedagogy, curriculum, and assessment strategies, we fail our students and jeopardize our own futures (Willms, 2003; Willms \& Flanagan, 2007; Willms, Friesen \& Milton, 2009; Tapscott, 1998; Prensky, 2005; Gilbert, 2007; Robinson, 2009). Students have changed over the last twenty years; perhaps as a result of a technology rich upbringing, they appear to have "different" needs, goals, and learning preferences than students in the past. We must better understand these youth to determine how to best engage them in learning; yet, there is a notable lack of "student voice" or student perspectives in the literature on student engagement. That said, some critics (Carlson, 2005; Carnivale \& Young, 2006; Bennett, Maton \& Kervin, 2008) do not believe today's students require special educational concessions. In fact, they believe we are dumbing down an entire generation through coddling. As "Professor Baron" is quoted in S. Carlson (2005): It is very common to hear people say, 'Here's the Millennial or the digital generation, and we have to figure out how they learn. Poppycock. We get to mold how they learn.' Administrators push professors to use technology in the classroom because they believe that is what today's students want, says Ms. Baron. And faculty members feel pressured to shorten lectures, increase groupdiscussion time, and ignore the "multitasking" student who is e-mailing his friends in the back of the room -- all to attract and satisfy a generation that doesn't have the discipline of its predecessors. 'We think that the students will come if we teach in a way that meets the expectations, we have of what the students want. At some point, what we are doing is killing higher education' (Carlson, 2005). However, this view is a minority; the majority of the literature we read embraces the idea of changing education. In fact, most educators practically implore transforming education and pedagogy from Kindergarten through postsecondary and strongly believe we fail to meet the needs of students who have grown up in a digital world and are heading into different cultural and economic futures rich in ever-advancing technology and information (Project Tomorrow, 2010). Today's world absolutely requires collaborative critical thinkers, creative and courageous innovators, and true lifelong learners (Prensky, 2005; Tapscott, 1998; Robinson, 2009). When we sift the literature for common strategies to improve student engagement in learning, a rather clear pattern of practices has emerged and certain "best practices" were recommended and repeated. For example, Windham recommends that, to engage learners in learning, new educational curriculum and activity must include - "Interaction, Exploration, Relevancy, Multimedia and Instruction" (pp 5.7-5.9). Her themes echo throughout the literature. Various elements of Windham's list are shared by S.D. Willms (2003), G. Claxton (2007), L.E. Hay (2000), K. Barnes, R. Marateo, \& S.P. Ferris (2007), J. Dunleavy \& P. Milton (2009), and OECD (2008) to name a few. We have synthesized the following categories from our reading and will use these to elaborate further: (1) Interaction, (2) Exploration, (3) Relevancy, (4) Multimedia, (5) Instruction, and (6) Authentic assessment.

\section{Method}

In order to determine the extent of the problem of organizing cognitive activities in the educational process (development, cognition, learning) we conducted an ascertaining experiment focused on the full employment of pupils' cognitive resources while guaranteeing the elimination of "extraneous factors" which are of no relevancy to the learning process.

In the course of th

e experiment, pupils ib grades $8-10$ grades were asked to complete two tasks:

- Task №1. What do you associate with the word "language”? Make an associogram. 
- Task №2. Write an essay on the following topic: "My native tongue is my wealth" (250-300 words), expressing your ideas on your mother tongue and its impact on your life, knowledge, and experience.

When conducting the experiment, we proceeded from the assumption that the cognitive act (and completing each task was a cognitive act) is manifested in language. Correlated with the specificity of perceiving reality, an act of cognition demonstrates the particular features of human information processing (Kagan 1974, p.7), which makes it possible to interpret the pupils' answers correctly.

Task 2 is to a certain extent correlated with Piaget's method for studying moral development (Miller 2002, p.331). The pupils had to refer to their personal experience and therefore had to make a moral choice.

In analyzing the pupils' written answers, the following aspects were taken into consideration:

1. Correlation between the provided information and concrete events or phenomena as well as the apt use of citation, since these factors point to the respondent's conception of the world.

2. The correlation between the concrete and the abstract, i.e. the use of definitions and their range (extended or reduced; borrowed or phrased independently) since these factors are directly related to the ideas expressed by the schoolchildren.

3. The presence of the agent and subjective evaluation in the respondent's text; the use of symbols, metaphors and so on, since these factors indicate the significance of the respondent's past experience for his or her creative processing of new meanings.

With the help of these three aspects, it is possible to determine the pupils' knowledge, their ability to think (i.e. to use their knowledge), as well as their ability to make wide use of their experiences.

The aforementioned points correspond to the criteria familiar to the participants in the experiment. While completing the tasks, they knew that their answers would be assessed according to

- the scope of the realized meanings;

- the degree of comprehending the problem;

- content emotionality;

- the relevance (adequacy) of the employed means.

As is known, individual features of the speech-thinking activity are manifested not only in the perception of the world, but also in understanding it, as well as in the interpretation of individual facts of reality. The knowledge of the criteria was assumed to help the pupils make their speech-thinking activity productive and fully realize their intellectual resource. On the one hand, the associogram and the essay were to reveal the respondents' subjective experience; on the other hand, the respondents' answers were to reflect their knowledge about the outside world, which might be more or less explicit. The respondents were free to determine not only the object of their thoughts and what to think about it, but also how to do it. Besides, the aforementioned criteria were supposed to be conducive to concentration and self-reflection. The tasks offered to the pupils aimed:

- to intensify the work of psycho-physiological mechanisms of speech and speechthinking on the whole;

- to make the respondents refer to their personal cognitive experience; 
- to broaden the pupils' horizons through specifying the existing knowledge and acquiring new knowledge;

- to make the respondents aware of their cultural identity.

The nature of the tasks ensured the formation of a linguistic (speech) mechanism as well as the creation in the respondents' long-term memory of cognitive structures enabling them to be aware of themselves as representatives of their native culture.

One of the important problems of education - the problem of teaching methods - remains relevant both in theoretical and in practical terms. Depending on its decision is itself the learning process, the activities of teachers and students, therefore, the result of learning in higher education in general. Let us examine one of the classifications - methods of classification by nature (degree of autonomy and creativity) of students in the activities. This classification I.Ja. Lerner (1981) proposed and M.N. Skatkin (1986). They noted that many of the previous approaches and teaching methods based on differences in their structures or external sources. Since the learning success to a great extent depends on the direction and the intrinsic activity of the trainees, the nature of their activities, it is the nature of the activity, the degree of selfreliance and creativity and should be an important criterion for the choice of methods. I.Ja. Lerner (1981) and M.N. Skatkin (1986) offered distinguish five methods of learning, and in each subsequent level of activity and independence in activities of students is growing. 1. The explanatory and illustrative method. Students are taught in lectures of educational methodical literature or through the on-screen manual in a "ready" state. Perceiving and comprehending the facts, evaluations, conclusions, students remain within the framework of reproductive thinking. In high school, this method is most widely used to transfer large amounts of information. 2. Reproductive method. This includes the use of a study on the basis of a sample or regulations. Activities of trainees is algorithmic in nature, ie, carried out according to the instructions prescribed by the rules in similar, similar to the sample shown situations. 3. The method of presentation of the problem. Using a variety of sources and resources, teacher before to present the material, raises the problem, forms a cognitive task, and then, revealing evidence of the system by comparing the point of view of the different approaches, shows a way to solve cognitive problems. Students how to become witnesses and accomplices of scientific research. 4. Part of the search or heuristic method. It consists in the organization of an active search for solutions put forward in the training of cognitive tasks or under the supervision of a teacher, or on the basis of heuristic programs and guidelines. The process of thinking becomes a productive character, but gradually guided and controlled by the teacher or by the students themselves based on the work of the programs and textbooks. This method, which is one of the varieties of heuristic conversation, - a proven way of thinking activation, field of interest to the knowledge at seminars and colloquia. 5. Research method. After reviewing the material, posing problems, objectives and a brief verbal or written instruction, students independently study the literature sources are observations and measurements, as well as perform other actions exploratory nature. Initiative, independence, creative search are shown more fully in the research activities. Methods of study directly grow into methods of scientific research.

\section{Results}

The analysis of associations caused by the word "language" shows that most of them reflect the respondents' ideas of reality on the elementary level. They are not incorporated into the system of their other knowledge but demonstrate a direct connection or interaction between objects. Thus, the most frequently mentioned associations with the notion of "language" were "a speech organ" (42), "a word" (54), "Russian" (33), "foreign" (33), "speech" (62), "communication" (40), and "language" (sign / programming / mathematical) (22). 


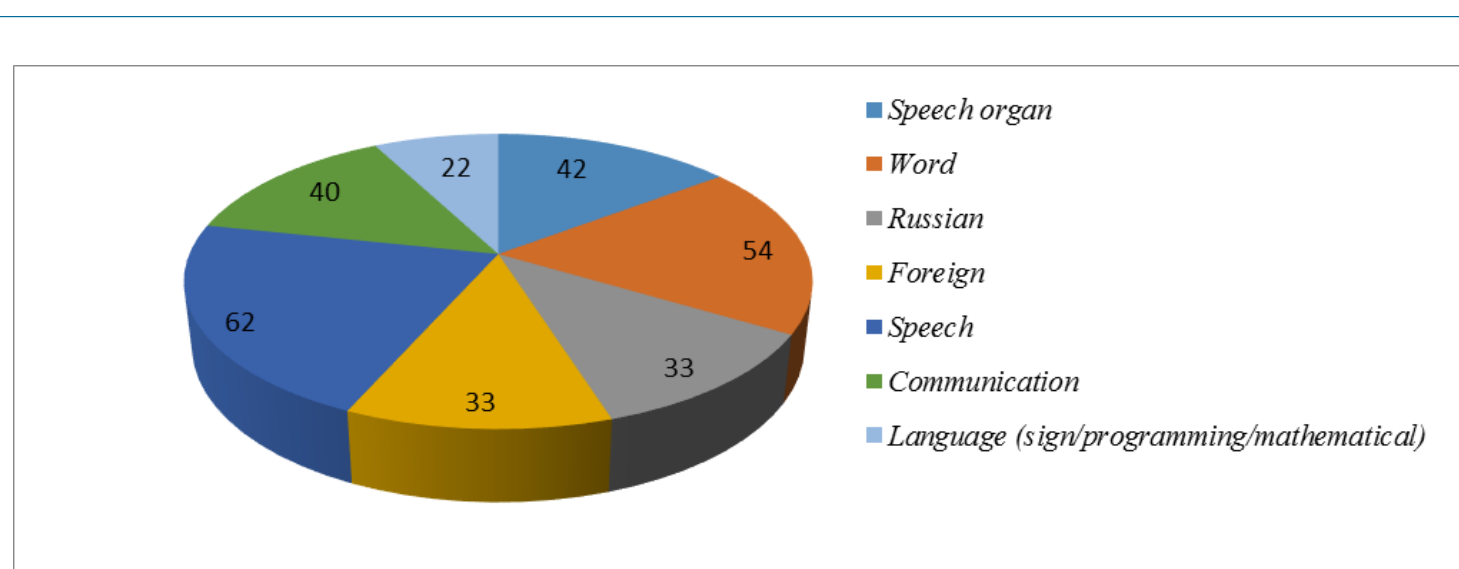

Figure 1. Associations on the elementary and basic levels

The respondents' associations on the elementary and basic levels include both concrete and abstract notions. For example, language - a speech organ, language $-\mathrm{a}$ word, language $-\mathrm{a}$ sentence, language - a mouth, language - food, language - teeth etc. (concrete notions); or language - literature, language - a means of expression, language - eloquence, language nationality, language - a nation (abstract notions). All of them reflect the schoolchildren's picture of the world, their life experience and perception of the existing lifestyles and mundane activities. The mundane picture of the world is based on a significantly simplified variant of some sensible, understandable, and practical things.

Yet, there are also conceptual associations resulting from processing information and the consequent emergence of complex logical and conceptual connections that occurs in the human brain; for example, "language" is "culture" (27), "wealth" (10), "traditions" (7), "love" (4), "beauty" (4), "greatness" (4), "pride" (4), or "freedom" (3).

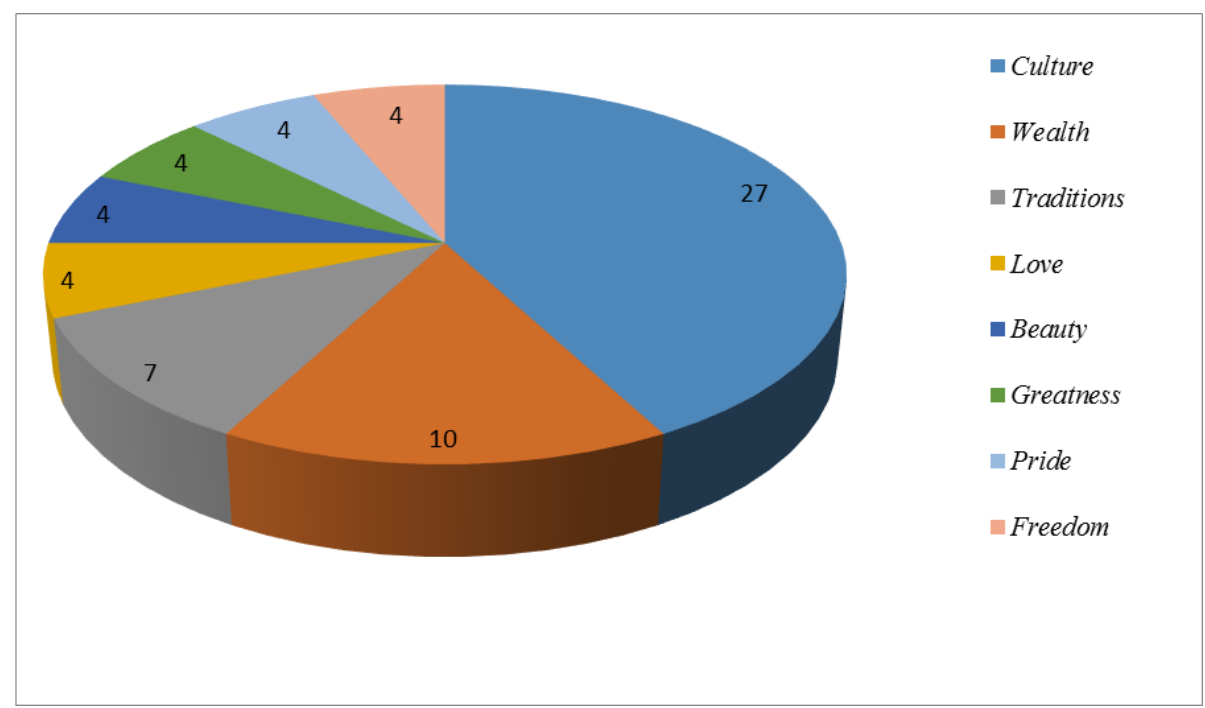

Figure 2. Conceptual associations

These examples testify to the fact that while completing the tasks, the respondents made use of information referring to various spheres of life and stored on different levels of consciousness. While creating the associative series, the pupils considered their thoughts, feelings, emotions, remembered their individual life experience, used their take on the situation, identified their feelings with concrete words, and controlled their emotions. The broader and more diverse the pupils' knowledge, the richer their associations and, accordingly, the more original their products of thinking are.

A quantitative comparison and a qualitative interpretation of the results, which made it possible to establish the predominance of associations on the elementary and basic levels, indicate 
the inadequate development of the pupils' cognitive structures necessary for representing the picture of the world.

This conclusion is confirmed by the results of the second task. Out of 203 participants, 95 did not complete the task, 65 completed it partially, and only 43 pupils completed the task.

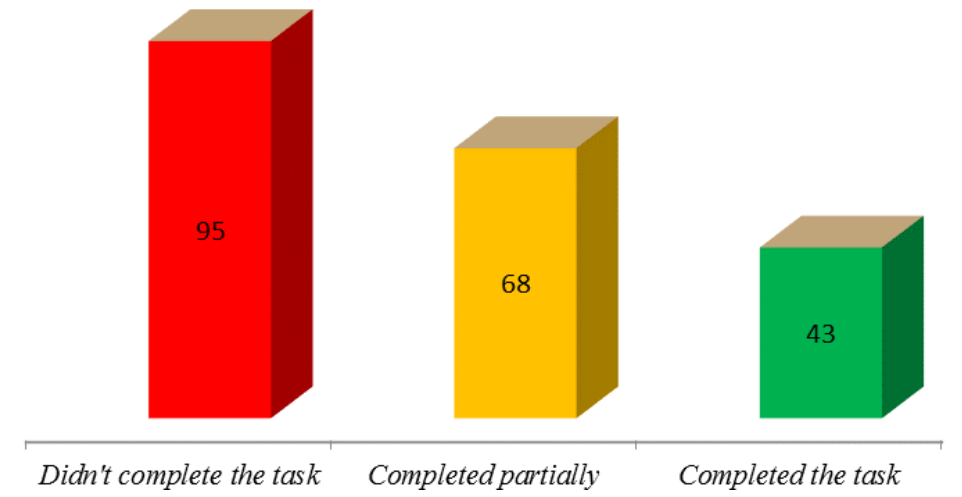

Figure 3. Solving a speech-thinking problem (quantitative index)

The qualitative evaluation of the essays indicates that while solving a speech-thinking problem, the pupils were able to make use of their knowledge of the outside world with a varying degree of success. Some essays are distinguished by a high level of problematicity, which testifies to the authors' intensive speech-thinking activity. The pupils managed to provide the key information related to the topic and to select facts corroborating the arguments put forward in the essay. They succeeded in establishing cause and effect relationships, in comparing and contrasting facts and performing other mental acts based on the operations of analysis, synthesis, induction, deduction, abstraction, inference etc.

The depth of understanding the problem manifested itself in the ability to express one's thoughts and feelings, as well as in a detailed and well-grounded narration. The pupils wrote about things that were important to them, often referring to their own (individual) life experience, which evoked an interested and emotional attitude to the discussion point. Instances of using personally significant, emotionally colored lexical items or metaphors expressing the respondents' attitude to objective reality are frequent. This manifestation of individuality and originality in the answers indicate the functioning of creative thinking in the course of cognitive activity. The excerpts from the respondents' essays cited below illustrate the aforementioned thesis.

"The Russian language is one of the most beautiful languages in the world. It is a mirror of our culture. Russia would be different without it. We should learn our native tongue enthusiastically because doing it is akin to looking for treasure on the bottom of an ocean, meaning that it isn't easy. Yet, if you have faith in yourself and if you tell yourself "I'll manage to do it!", it won't seem such a difficult task... Language means knowledge. And knowledge is the kind of wealth that no one will ever take away from us..."

"My native language helped me to learn about the world, to discover the enormous and magical world of life already when I was a child..."

"We use sincere words for our friends, we use tender words to open up our hearts to the ones we love, we use harsh and angry words to fight our enemies..."

“... further on I had to learn a few more languages. After learning them for eight years, I still haven't changed my opinion that there's no other language like one's mother tongue..." 
"When I was a little girl, I used to think that it wasn't necessary to study one's mother tongue, that one could easily do without it. Only now do I understand that I was mistaken. Once I wanted to read a thick book with lovely golden letters on its colourful cover. When I opened it, I saw a lot of letters and couldn't read a single sentence. I felt disappointed and ashamed..."

“...in the Russian language, there are a lot of synonyms to denote a blizzard, a snowstorm, an ice storm, snowfall. Such peculiarities of a language help us to get to know peculiarities of the native speakers, the place they live in, their lifestyles... It is unreasonable to try to understanding a foreign language without knowing your own. In my experience, my knowledge of Russian was a great help to me in learning English..."

"The Russian language matters a lot to me as a poet with the small letter "p". This language is most suitable for prose and poetry. It is capable of selecting words which will touch the reader deep inside, cheer him up, make him think. Using the incredible wealth of our language, a poet can create breathtaking pictures in the reader's mind..."

It is obvious that the pupils' statements are remarkably wide-ranging; the respondents use various facts of objective reality, i.e. the essays are characterized by rich content and sound arguments.

One of the means of argumentation is citation. Let us provide examples from the participants' essays.

"I personally have always taken pride in the fact that my native tongue is Russian. Only when I speak it do I feel the greatness and power of the Russian nation, its power and authority. Russian enables me to talk, think, and reason. To reason like a personality, to reason like a Russian person, which is undoubtedly very important? As R. Descartes said, 'Cogito ergo sum'...”

«I.S. Turgenev also wrote, ' $\ldots$ oh great, powerful, righteous, and free Russian tongue! But for thee, how not to fall into despair, seeing all that happens at home?' ..."

Citation reflects the development of the pupils' thinking process, from their realising the problem situation to making a logical inference. In some cases, a quotation used to characterise "old" knowledge lays the foundation for its reconsideration and gives rise to new knowledge in the course of the speech-thinking activity. The participants in the experiment were able to make use of everything related to the discussion point, to correlate the known and the new, and to find the optimal way of expressing their thoughts and attitude to the subject-matter.

Yet, a considerable number of respondents (65) failed to raise a problem in their essays. Their knowledge is not incorporated into the general system of their acquired knowledge. Not all the pupils are capable of expressing their ideas consistently, or of analyzing and summing up certain facts and phenomena of objective reality. It is also necessary to point out that most of the pupils are unable to see the whole scope of meanings relating to the subject, to back up their statements with the help of concrete examples from their personal experience, or to use facts. Some of the respondents failed to express their ideas clearly. Their essays abound with repetitions and meaningless clichés used by the authors with the sole purpose of making the essay fit the word count. The use of personally unmotivated clichéd expressions made the statements stereotyped, superficial, and reduced their emotionality.

Here are a few examples. "It's not by chance that there are so many works of literature by outstanding authors dedicated to the Russian language. It is thanks to the Russian language that we can read famous novels, dramas, and poems by Russian classics such as Pushkin, Dostoevsky, Lermontov, Tolstoy, Bulgakov, Turgenev and others..." 
"In my opinion, one's native tongue plays a great role in shaping their personality and determines their fate to a degree... In conclusion I'd like to say that one's native tongue is something without which it's impossible to imagine a person. My native tongue is my everything..."

"One's native tongue is the greatest language of all languages. Its knowledge enables us to become well-rounded people. There are a lot of expressive means in our language which help us to make our speech more beautiful and diverse..."

"In my opinion, the Russian language is one of the greatest languages in the world. Russian is one of the best-known and most complex languages, and I'm proud of it. I think that my language is my wealth as we would be unable to communicate without it..."

"My native tongue is my wealth. And it's true. With the help of language a person does absolutely everything: talks, expresses his emotions, experiences joy and worries... Actually, the Russian language is very rich, great, powerful, boundless and truly perceptive. Thanks to Russian, nations can negotiate and communicate..."

"The role of my native tongue in my life is great as I'm learning it and developing it by means of writing essays on various and at the same time very interesting topics..."

As has already been mentioned, 95 participants failed to solve the speech-thinking problem or solved it on a very low level. It leads us to infer that the pupils do not possess sufficient knowledge, are unable to obtain, process and share it, and therefore are unable to cognize the world actively. In other words, they are not ready to realize their relationship with the outside world, to view themselves as personalities, citizens, and ethical individualities.

\section{Discussion}

It is obvious that the results of the described experiment clearly indicate that the organization of schoolchildren's cognitive activity requires changes which are primarily associated with managing the process.

We do not accept the ideas of Ron Paul, who suggested that parents should turn over the responsibilities of mastering a basic curriculum to their children (Paul 2013). A qualitative interpretation of the results of the experiment leads us to think about the need for a wellconsidered impact on pupils' cognitive and emotional-sensory spheres.

It also became obvious to us that the results of the experiment should be interpreted in a more detailed and comprehensive manner, taking into account W. James' research on associations, in which he argues that "all advance in knowledge must consist of both operations; for in the course of our education, objects at first appearing as wholes are analyzed into parts, and objects appearing separately are brought together and appear as new compound wholes to the mind. Analysis and synthesis are thus the incessantly alternating mental activities, a stroke of the one preparing the way for a stroke of the other..." (James 2001, p.154).

Different levels (from high to low) of cognitive abilities displayed by the participants in the experiment necessitates collecting additional data in the course of a new experiment, in which such factors as the character of the tasks and the level their problematic will remain the same. As to the study group and the content of the tasks, these factors will be changed. 
Thus, it will be possible to obtain information which is necessary to specify our hypothesis that the intentional development of cognitive mechanisms will lend a cognitive aspect to the process of cultivating morality as well as to development and learning.

On this basis, it is possible to implement educational adequacy which integrates axiological, humanitarian, and technological adequacy (see the works of E.I. Passov on the hierarchical system of principles in Methods as a theory and technology of education).

Since the experiment is conducted in the pupils' native tongue (Russian), its results can be used for any other school subject.

\section{Inference}

Answering the questions posed at the beginning of the article it is necessary to point out the following:

1) pupils should assimilate cognitive information on the basis of a special and carefully thought-out organization of the educational process, involving not only a variety of sources of information, but also a critical attitude to the information itself. This is all the more important considering that it is extremely difficult nowadays to detect signs of information distortion, because digital technology allows falsifying not only text but also images;

2) the process of assimilating cognitive information at school will be more productive if the given content is openly discussed, i.e. when the pupils and the teacher act as fullfledged subjects of the dialogue of cultures;

3) the development of cognition as a type of activity can be ensured only through the use of various modalities of the actors' experience in solving urgent problems. Therefore, the teacher must ensure the harmonization of the interaction of all the participants in the cognitive process

4) pupils can go beyond the information given not only due to the individualization of the educational process, but also in the process of shaping skills which are necessary for them to think over a speech act and which are supported by the logic of independent reasoning and relevant argumentation;

5) probably the most important thesis: cognition makes all the other types of activity value-orientation / labor / artistic activity, play, communication - relevant and tangible. The major result of the described processes is "the cultivation of a cognitive attitude to the world" implying "sensitivity to ideas, values and ideals" (Abulkhanova-Slavskaya 1980, p.118), which fully corresponds to the general goal of education - shaping a spiritual, that is, ethical, intellectual and skillful personality.

\section{References}

Abulkhanova-Slavskaya, K.A. (1980). Deyatel'nost' i psikhologiya lichnosti [Activity and personality psychology]. Moscow: Nauka.

Bruner, J. (1973) Beyond the Information Given: Studies in the Psychology of Knowing. NY: W.W. Norton \& Company.

Brushlinksky, A.V. (1990). Glavnoye - eto vzaimodeystviye cheloveka s mirom [The main thing is man's interaction with the world]. In: Deyatel'nost': teorii, metodologiya, problemy [Activity: theories, methodology, problems]. Moscow: Politizdat.

James, W. (2001). Psychology: The Briefer Course Paperback. NY: Dover Publications.

Kagan, M.S. (1974). Chelovecheskaya deyatel'nost' (Opyt sistemnogo analiza) [Human activity (A systemic analysis)]. Moscow: Politizdat.

Miller, S. (2018). Developmental Research Methods. NY: SAGE Publications. 
Passov, E.I. (2016). Obrazovaniye kak fenomen i metodika kak nauka: problema konvergentsii [Education as a phenomenon and Methods as a science: the problem of convergence]. Lipetsk: OOO "Izdatel"”.

Paul, R. (2013). The School Revolution: A New Answer for Our Broken Education System. NY: Grand Central Publishing.

Vygotsky, L.S. (1982). Myshleniye i rech'. Sobraniye sochineniy [Thinking and speech: Collected works: in 6 vols.] Vol. 2. V.V. Davydov, ed. Moscow: Pedagogika. 